\title{
Original Research \\ First aid practices, beliefs, and sources of information among caregivers regarding paediatric burn injuries in Harare, Zimbabwe: A cross-sectional study
}

\author{
Farai Chirongoma $^{1}$, Samson Chengetanai ${ }^{2}$, Cathrine Tadyanemhand ${ }^{1}$ \\ 1. Department of Rehabilitation, College of Health Sciences, University of Zimbabwe, Harare, Zimbabwe \\ 2. Division of Basic Medical Sciences, Faculty of Medicine, National University of Science and Technology, Bulawayo, Zimbabwe
}

Correspondence: Miss Cathrine Tadyanemhandu (cathytadya@gmail.com)

\begin{abstract}
Background
\section{Abstract}

While burns take seconds to occur, injuries incurred result in pain and undesirable long term effects that might take a lifetime to overcome. The study was carried out to determine the measures of first aid delivered by caregivers after a burn injury and sources of the information.
\end{abstract}

Methods

A cross- sectional study was carried out over a period of 3 months at two central hospitals in Harare. A questionnaire was administered to the caregivers of children within the age group of 0-60 months admitted in burns wards to elicit information on the circumstances of the burn injury and the first aid methods which were administered.

Results

Out of the 50 children who were recruited, $54.0 \%$ were females and the mean age was 29.5 months (SD=15.5). After the burn injury $30(60.0 \%)$ of the caregivers, cooled the burn injury with cold running water whilst some caregivers also applied eggs, margarine and some traditional herbs as first aid. The other practices reported by the caregivers included use of urine and crushed cockroaches after burn injury in $40(80.0 \%)$ whilst $20(40.0 \%)$ reported used aloe vera gel after a burn injury. About half of the caregivers got first aid information mainly from family members and very few indicated that the information was obtained from mass media, 3 (6.0\%).

Conclusions

The first aid measures used by the majority of caregivers were either incomplete or inadequate. Although some caregivers had adequate knowledge of what to do after an injury, there still was widespread use of alternatives therapies in burn management.

\section{Introduction}

Burns remain a significant cause of injury in the paediatric population worldwide despite the advancement in treatment of affected patients, as reflected by a decrease in morbidity and mortality associated with these injuries. ${ }^{1}$ Burn injuries have been reported to be high in children below the age of 14 and the incidence is particularly high in infants and toddlers, especially during the winter season., ${ }^{2,3}$ In Zimbabwe childhood burn injuries have emerged as a major public health problem, ${ }^{4}$ as noted in the other developing countries as well. First aid is emergency care or treatment given before regular medical aid can be obtained and it must be readily available, easy to use by the general public and not hinder professional examination or treatment of the wound at a later date. ${ }^{5}$ First aid after burn injuries should aim at providing analgesia and ideally halt the progression of injury. Appropriate and complete first aid given to the child immediately after injury is associated with significantly reduced re-epithelialization time for children with contact burns and results in positive clinical outcomes in the children at discharge from the hospital. ${ }^{5}$ The benefits of implementing the appropriate first aid treatment after a burn injury include; halting the progression of the burn, removing any noxious agents, providing pain relief and reducing oedema and increasing the rate of wound healing by promoting the rapid growth of epithelial cells. ${ }^{5}$ The recommended first aid treatment after a burn injury includes stopping the burning process, removing clothes or jewellery near the burnt area, cooling the burn for 10-30 min with cool or lukewarm water, keeping the patient warm, covering the burnt area with cling film, giving analgesia as well as seeking professional help. ${ }^{6}$ Use of inappropriate first aid measures is associated with infection as some of the items used are non-sterile and promote bacterial proliferation on the surface of the wound and use of ice or iced water leads to vasoconstriction which lead to hypothermia especially in children. ${ }^{5}$ Use of aloe vera has also been shown to be associated with significantly delayed wound healing and use of oils, vaseline, fats, flour, powdered chalk and creams which was believed to form effective air barrier was not beneficial and made secondary treatment by the doctor/surgeon more difficult. ${ }^{5}$ The aim of this study was to determine the measures of first aid delivered by caregivers in Harare, Zimbabwe after a burn injury and the sources of the information.

\section{Methods}

A descriptive cross sectional study was done at Parirenyatwa Group of Hospitals and Harare Central Hospital over a period of three months in the paediatrics burns wards. The two hospitals are the largest government hospitals in Harare and have also specialised burns units for major burns admission. The admission criteria for the hospitals are as follows: any burn affecting greater than $10 \%$ of the TBSA, children with $8-10 \%$ burns or more, burns of special regions like face, neck, hands and feet, perineum and joints irrespective of TBSA, circumferential burns, electrical, lightning and chemical burns, lesser burns associated with inhalational injury, significant pre-existing medical disorders and very young patients or suspected abuse. The majority 
Table 1: Sociodemographic characteristics of the children who sustained burn injuries and their caregivers $(\mathrm{N}=50)$

\begin{tabular}{|c|c|c|}
\hline $\begin{array}{l}\text { Mean child age (months) } \\
\pm \text { standard deviation (SD) }\end{array}$ & & $29.5 \pm 15.5$ \\
\hline \multirow{2}{*}{$\begin{array}{c}\text { Child gender } \\
\text { n (\%) }\end{array}$} & Male & $23(46.0)$ \\
\hline & Female & $27(54.0)$ \\
\hline \multirow{3}{*}{$\begin{array}{c}\text { Caregiver relationship to child } \\
\text { n (\%) }\end{array}$} & Mother & $39(78.0)$ \\
\hline & Parents & $6(12.0)$ \\
\hline & Grandmother & $5(10.0)$ \\
\hline \multirow{2}{*}{$\begin{array}{c}\text { Caregiver marital status } \\
\text { n (\%) }\end{array}$} & Married & $42(84.0)$ \\
\hline & Formerly married & $8(16.0)$ \\
\hline \multirow{3}{*}{$\begin{array}{c}\text { Residential area } \\
\text { n (\%) }\end{array}$} & Urban & $30(60.0)$ \\
\hline & Periurban & $12(24.0)$ \\
\hline & Rural & $8(16.0)$ \\
\hline \multirow{3}{*}{$\begin{array}{c}\text { Caregiver educational level } \\
\text { n (\%) }\end{array}$} & Primary & $5(10.0)$ \\
\hline & Secondary & $38(76.0)$ \\
\hline & Tertiary & $7(14.0)$ \\
\hline \multirow{3}{*}{$\begin{array}{c}\text { Caregiver employment status } \\
\text { n (\%) }\end{array}$} & Unemployed & $22(44.0)$ \\
\hline & Formally employed & $17(34.0)$ \\
\hline & Informally employed & $11(22.0)$ \\
\hline $\begin{array}{l}\text { Mean household members } \\
\mathrm{n} \pm \text { SD }\end{array}$ & & $5.04 \pm 1.9$ \\
\hline
\end{tabular}

Table 2: Burn characteristics, supervision, and complications $(\mathrm{N}=50)$

\begin{tabular}{lll}
\hline & Characteristic & Frequency \\
\hline $\begin{array}{l}\text { Cause of burn } \\
\text { n (\%) }\end{array}$ & Scald & $22(44.0)$ \\
& Flame & $14(28.0)$ \\
& Contact & $14(28.0)$ \\
\hline Time of burn & Morning (0:00 to 11:59) & $16(32.0)$ \\
n (\%) & Afternoon (12:00 to 17:59) & $10(20.0)$ \\
& Evening (18:00 to 23:59) & $24(48.0)$ \\
\hline Primary supervisor & Mother & $35(70.0)$ \\
n (\%) & Sibling & $2(4.0)$ \\
& Relatives & $8(16.0)$ \\
& Housekeeper & $5(10.0)$ \\
\hline Complications & Contractures & $11(22.0)$ \\
n (\%) & Wound infection & $14(28.0)$ \\
\hline
\end{tabular}

of the children admitted in the burns ward would have sustained burns of special regions irrespective of the TBSA. The children admitted in the burns wards are patients with moderate burns, as severe burns will require long term special care and should be managed in a suitable specialised burns units in the respective hospitals. Children in the age group of zero to five years admitted in the burns wards in the two hospitals and their caregivers were recruited to participate in the study. Caregivers of the children consented to take part in the study and to have data relating to their children accessed. Ethical approval was obtained from the Joint College of Health Sciences and Parirenyatwa Group of Hospitals Research Ethics Committee (JREC Ref: 381/14) and the Institutional Review Boards of the two hospitals. Collection of data was via a researcher-administered questionnaire with a total of twenty two questions. Information was gathered through interviewing the caregiver as well as review of patients' notes and examination of the patient. For the purpose of the study, the caregiver was defined as the the individual who spent most of the time with the child overseeing the child's care during the child's http://dx.doi.org/10.4314/mmj.v29i2.14 admission. The questionnaire had three sections which included the demographic section eliciting information on the child's age, gender, place of occurrence of the burn injury, caregiver's gender, level of education, marital status and employment status. The last section collected information on the burn history which included: cause, severity, individual who was supervising the child on the day of the injury, complications which resulted and the first aid or home based treatment administered to child at home when the burn injury occurred. Some other first aid practices which the caregivers had heard about but not necessarily have used when the burn injury occurred where documented. The first aid treatment was defined as appropriate or inappropriate based from review of articles which highlighted the best first aid measures to be encouraged and measures which were deemed inappropriate. ${ }^{5-7}$

\section{Results}

\section{Demographics of children and the caregivers}

Of all the children with burns, $23(46.0 \%)$ were males and $27(54.0 \%)$ were females. Their mean age was 29.5 months $(\mathrm{SD}=15.5)$. Most of the children and their caregivers, 30 $(60 \%)$ resided in urban areas and only $8(16 \%)$ were from the rural areas. The majority $42(84.0 \%)$ of the caregivers were married.

Of all the caregivers, $45(90.0 \%)$ were either one of the parents but mostly the mother. A total of thirty eight (76.0\%) caregivers had a highest level of education of secondary level and seven $(10.0 \%)$ studied up to tertiary level. The majority, $22(44.0 \%)$ of caregivers were unemployed and 17 $(34.0 \%)$ were formerly employed. Most of the households, $43(86.00 \%)$ which the caregivers came from had a total number of people living there who fell within the class of 0-7 people with the mean members of the household being $5.04 \pm 1.88$ people (Table 1$)$.

\section{Burn characteristics, severity and complications}

The main cause of burns in this cohort was scalding, 22 (44\%). Most of the burns occurred in the evening (1800$2400 \mathrm{hrs}$ ) whilst the child was under the mother's supervision. The total body surface area (TBSA) ranged between 1-28\% with a mean of $8.9 \%(\mathrm{SD}=7.1)$ and the complications which developed in half of the children were wound infection and contractures (Table 2).

\section{First aid administered by caregivers and sources of first aid information}

There were $10(20.0 \%)$ caregivers who did not provide any form of some first aid to the children when the burn injury occured. About $18(36.0 \%)$ of the caregivers only used one method whilst $22(44.0 \%)$ used more than one method of first aid. Of the 22 caregivers who reported to have used more than one method of first aid, 13(52.0\%) of the children developed complications and infection was the common complication in the majority $9(36.0 \%)$ of the children. From the 10(20.0\%) caregivers who did not use any form of first aid, $6(24.0 \%)$ children were reported to have developed complications, with infection being noted in one child. There was no significance difference between the complications which developed and the number of first aid methods used [ $\mathrm{p}$ (Fisher's Exact $)=0.12]$. The majority of the caregivers, $30(60.0 \%)$ cooled the burn injury with cold running water. Some caregivers also applied eggs, margarine and some traditional herbs as first aid. (Table 3). There was a statistically significant difference between the complications 
which developed and the appropriateness of the first aid, with majority of the children developing infection after inapproprite methods administered $(\mathrm{X} 2(2)=29.848 \mathrm{p}=.0001)$. Apart from the first aid methods highlighted on the questionnaire, the caregivers also indicated other methods. The common practices included use of urine and crushed cockroaches after burn injury in 40 (80.0\%) of the participants. Others reported use of aloe vera gel, 20(40.0\%); gentle magic serum, 16(32.0\%); flour, $10(20.0 \%)$ and lotions like camphor cream in

Table 3: First aid measures administered by caregivers $(\mathrm{N}=50)$

\begin{tabular}{|c|c|c|c|c|}
\hline $\begin{array}{l}\text { First aid measures delivered by } \\
\text { caregivers }\end{array}$ & $\begin{array}{c}\text { Yes } \\
\text { n }(\%)\end{array}$ & $\begin{array}{c}\text { No } \\
\text { n }(\%)\end{array}$ & $\mathrm{X}^{2}$ statistic* $^{*}$ & P-value* \\
\hline Cooled the area with running water & $30(60.0)$ & $20(40.0)$ & 5.811 & 0.050 \\
\hline $\begin{array}{l}\text { Ensuring own safety and removal of heat } \\
\text { source }\end{array}$ & $16(32.0)$ & $34(68.0)$ & 2.583 & 0.27 \\
\hline Proper positioning of the child & $8(16.0)$ & $42(84.0)$ & 0.697 & 0.71 \\
\hline $\begin{array}{l}\text { Application of cold water towel and } \\
\text { vaseline }\end{array}$ & $9(18.0)$ & $41(82.0)$ & 0.790 & 0.68 \\
\hline $\begin{array}{l}\text { Removal of clothes sticking to the body } \\
\text { after burn injury }\end{array}$ & $10(20.0)$ & $40(80.0)$ & 0.915 & 0.63 \\
\hline $\begin{array}{l}\text { Breaking of the blisters and removal of } \\
\text { peeled skin }\end{array}$ & $7(14.0)$ & $43(86.0)$ & 0.789 & 0.67 \\
\hline $\begin{array}{l}\text { Application of ice, eggs, margarine and } \\
\text { traditional herbs }\end{array}$ & $17(34.0)$ & $33(66.0)$ & 23.064 & 0.0001 \\
\hline
\end{tabular}

$9(18.0 \%)$ of the participants.

About half of the caregivers got information on first aid information mainly from family members and friends whilst very few indicated that the information was obtained from mass media, $3(6.0 \%)$ (Table 4).

\section{Discussion}

First aid of burns reduces the severity and depth of tissue damage and improves outcomes, including a reduction in hospitalization time and surgical intervention. ${ }^{5}$ It therefore becomes very important for the population with a high burden of burns, to be well informed about the appropriate and effective first aid measures to be done following a burn injury.

From the published work, the current recommendations for the first aid treatment of burn injuries should be to use cold running tap water (between 2 and 15 0C) on the burn, not ice or alternative plant therapies. ${ }^{5}$ Basing from these recommendations and results of our study, it shows that the knowledge of first aid in burns is poor among the caregivers. Some caregivers had some knowledge on the appropriate first aid treatment methods to be used whilst others had no knowledge at all as the first aid methods they used were contraindicated. This correlates with the findings from some studies done in the United Kingdom which concluded that knowledge of burns first aid among parents is inadequate and correlates with lower socioeconomic groups. ${ }^{6,7}$

It is not certain whether some of the alternatives therapies used for burns do not cause some of the complications. Our results showed a significance association between use of inappropriate methods, especially use of ice, eggs, margarine, traditional herbs and development of infection as a complication in the children. The other methods the caregivers also highlighted to be the other methods they know, it cannot be proved if they did not actually use them on the burn injury their children sustained. The methods used by the caregivers were easy to use and readily available to the general public but it is not certain whether these methods do not hinder professional examination and/or treatment of the wound at a later date. Alternatives therapies such as plant herbs, margarine and were given to provide analgesia whereas; aloe vera gel was reported to decrease inflammation. Gentle magic serum and crushed cockroaches
Table 4: Sources of first aid information for caregivers $(\mathrm{N}=50)$

\begin{tabular}{lc}
\hline $\begin{array}{l}\text { Primary } \\
\text { information source }\end{array}$ & Frequency (\%) \\
\hline Books & $6(12.0)$ \\
School & $5(10.0)$ \\
Internet & $11(22.0)$ \\
Mass media & $3(6.0)$ \\
Family member & $25(50.0)$ \\
\hline
\end{tabular}

were reportedly applied to improve the resultant scar post burn injury. Similar alternative therapies have been reported as common practice after a burn injury in other African countries like South Africa and Nigeria., ${ }^{8,9}$ The other alternative therapies which were reported from South Africa and Nigeria but not common in caregivers in our study were pap, chalk, cow dung and salt. It was also noted that even in some European countries like Turkey and the United Kingdom, inappropriate methods were popular after a burn injury and these included yoghurt, toothpaste, tomato paste, ice, chalk, raw egg whites, or sliced potato. ${ }^{6,10}$ It is indicated that preventing exposure to air after a burn injury alleviates pain and reduces further damage ${ }^{5}$; this intended outcome could account for some of the behaviours observed in some caregivers who ended up applying margarine, lotions and flour on the burn site.

The information about practicing the appropriate methods of first aid after burn injury have to be communicated to all caregivers as some caregivers were not aware of the benefits or harm of each method. It is therefore important for all the caregivers to be informed of the appropriate practice to do following a burn injury and the associated benefits. The source of first aid information after a burn injury was also seen to vary. Caregivers in urban areas have access to television, radio and internet therefore, they are most likely to be aware of the appropriate measures to be done if any campaigns or audio presentations are done on burn management. On the contrary, caregivers from rural areas do not have access to mass media hence they rely more on 
the information from local people. Some have to travel very long distances to the nearest clinic or hospital but they can easily get help from traditional healers who usually reside within easy reach of general populace. Traditional healers and older relatives will promote use of plant therapies after a burn hence plant therapy becomes the common method of treatment following burns in rural areas. In the case of rural areas, the village health workers have to be fully utilized so that they can deliver frequent burns management campaigns for the local people and also the traditional healers and the health professionals have to work together in order to provide the best treatment to people which is not detrimental.

\section{Conclusions}

The first aid methods used by the caregivers were either incomplete or inadequate. Although some of the caregivers had adequate knowledge of what to do after an injury like cooling the area over running water, there was widespread use of alternatives therapies in the management of the burns and source of the information was mainly from a family member.

\section{Acknowledgements}

Would like to thank Professor Chidzonga, Mr Muguti, University of Zimbabwe, College of Health Sciences, the staff members of the burns wards at Parirenyatwa Group of Hospitals and Harare Central Hospital, and the participants, caregivers, and children who took part.

\section{Competing interests}

All authors declare that they have no competing interests related to this work.

\section{References}

1. Toon MH, Maybauer DM, Arceneaux LL, Fraser JF, Meyer W, Runge A, Maybauer MO. Children with burn injuries-assessment of trauma, neglect, violence and abuse. J Inj Violence Res. 2011; 3(2): 98-110.

2. Asuquo ME, Ekpo R, Ngim O. A prospective study of burns trauma in children in the University of Calabar Teaching Hospital, Calabar, south-south Nigeria. Burns. 2009;35(3):433-6.

3. Fadeyibi IO, Mustapha IA, Ibrahim NA, Faduyile FI, Faboya MO, Jewo PI, Ademiluyi SA. Characteristics of paediatric burns seen at a tertiary centre in a low income country: A five year (2004-2008) study. Burns. 2011;37(3):528-34.

4. Mzezewa S, Jonsson K, Åberg M, Salemark L. A prospective study of suicidal burns admitted to the Harare burns unit. Burns. 2000;26(5):4604.

5. Cuttle L, Kravchuk O, Wallis B, Kimble RM. An audit of first-aid treatment of pediatric burns patients and their clinical outcome. J Burn Care Res 2009;30:1028-34.

6. Graham HE, Bache SE, Muthayya P, Baker J, Ralston DR. Are parents in the UK equipped to provide adequate burns first aid? Burns 2012;38:438-43.

7. Davies M, Maguire S, Okolie C, Watkins W, Kemp AM. How much do parents know about first aid for burns? Burns 2013; 39: 1083 - 1090.

8. Jonkheijm A, Zuidgeest JH, van Dijk M, van As B. Childhood unintentional injuries: Supervision and first aid provided. Afr J Paediatr Surg 2013;10:339-44.

9. Fadeyibi IO, Ibrahim NA, Mustafa IA, Ugburo AO, Adejumo AO, Buari A. Practice of first aid in burn related injuries in a developing country Burns 2015;14(6): 1322-32.

10. Karaoz B. First-aid Home Treatment of Burns Among Children and Some Implications at Milas, Turkey. Journal of emergency Nursing 2010; 36(2): 111-114. 